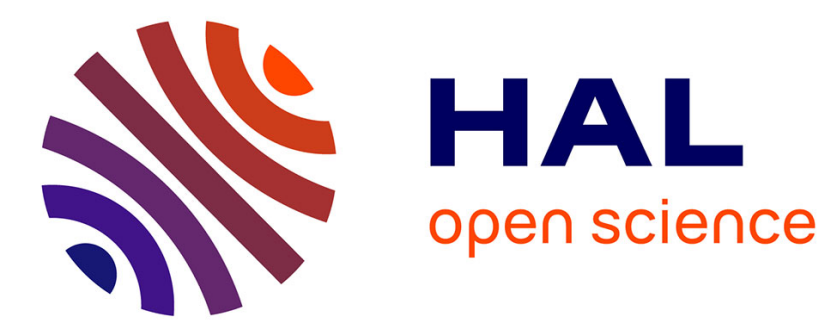

\title{
Eye Movements Data Processing for Ab Initio Military Pilot Training
}

Emilien Dubois, Colin Blatter, Cyril Camachon, Christophe Hurter

\section{To cite this version:}

Emilien Dubois, Colin Blatter, Cyril Camachon, Christophe Hurter. Eye Movements Data Processing for Ab Initio Military Pilot Training. Intelligent Decision Technologies Proceedings of the 7th KES International Conference on Intelligent Decision Technologies (KES-IDT 2015), 39, Springer, pp 125135, 2015, Smart Innovation, Systems and Technologies, 978-3-319-19856-9. 10.1007/978-3-319-198576_12. hal-01166484

\section{HAL Id: hal-01166484 \\ https://hal-enac.archives-ouvertes.fr/hal-01166484}

Submitted on 23 Jun 2015

HAL is a multi-disciplinary open access archive for the deposit and dissemination of scientific research documents, whether they are published or not. The documents may come from teaching and research institutions in France or abroad, or from public or private research centers.
L'archive ouverte pluridisciplinaire $\mathbf{H A L}$, est destinée au dépôt et à la diffusion de documents scientifiques de niveau recherche, publiés ou non, émanant des établissements d'enseignement et de recherche français ou étrangers, des laboratoires publics ou privés. 


\title{
Eye Movements Data Processing for Ab Initio Military Pilot Training
}

\author{
Emilien Dubois ${ }^{1}$, Colin Blättler², Cyril Camachon², Christophe Hurter ${ }^{1}$ \\ ${ }^{1}$ ENAC, Laboratoire d'Informatique Interactive (LII), Toulouse, France \\ (emilien.dubois, christophe.hurter)@enac.fr \\ ${ }^{2}$ CReA, Facteurs Humains et Milieux Opérationnels (FHMO), Salon-de-Provence, France \\ (colin.blattler, cyril.camachon)@defense.gouv.fr
}

\begin{abstract}
French $a b$ initio military pilots are trained to operate a new generation of aircraft equipped with glass cockpit avionics (Rafale, A400M). However gaze scanning teachings can still be improved and remain a topic of great interest. Eye tracking devices can record trainee gaze patterns in order to compare them with correct ones. This paper presents experimentation conducted in a controlled simulation environment where trainee behaviors were analyzed with notifications given in real-time. In line with other research in civil aviation, this experimentation shows that student-pilots spend too much time looking at inboard instruments (inside the cockpit). In addition, preliminary results show that different notifications bring modifications of the visual gaze pattern. Finally we discuss future strategies to support a more efficient pilot training thanks to real-time gaze recording and its analysis.
\end{abstract}

Keywords: eye tracker; gaze behavior; military student pilots; flight simulator; automation issue.

\section{Introduction}

During summer 2012, the French Air Force academy replaced the analogical conventional cockpits of training aircraft by numerical glass-cockpits with sophisticated automation. The glass cockpit (see Fig. 1. for illustration) replaces the traditional electro-mechanical cockpit dials (altimeter, airspeed, turn and bank, vertical speed, altitude and heading) with two screens: the Primary Flight Display (PFD) and the MultiFunction Display (MFD). The PFD displays all of the information provided by the separate dials found in the traditional cockpit [22]. This change was an opportunity to study the impact of the modern cockpit environment in ab-initio flight training [1]. Up to now, the transition to a modern cockpit environment occurred late in the French Air Force pilot training. However, teaching glass-cockpit earlier in pilot training raises the question of how the young pilots should be trained. Indeed, instructional techniques have been optimized over a long period of time for aircraft equipped with steam gauges [2]. Traditionally, pilots had to learn how to scan the six basic aircraft control steam gauges (attitude, altitude, airspeed, heading, climb rate and turn direction and rate) together with the outside environment. They were advised to look inside 
the cockpit no more than $4-5$ seconds for every 16 seconds spent scanning the outside world [3]. Several studies stated that pilots had not achieved optimized visual scanning [4]. In addition, one of the main pitfalls is to spend too little time looking out the window: "too much head-down time" [5].

The modern glass cockpit technology was supposed to make the scan pattern easier and to help improve pilot's situation awareness [6]. To the best of our knowledge, there is no evidence that this is the case for novice pilots. Currently, there is no standardized "scan technique" training at the French Air Force Academy regarding glass cockpit management. The current teaching methods are based on flight instructors' experience, which is mostly acquired on conventional airplanes. According to French Air Force instructors, glass-cockpits really draw student pilot attention inside the airplane. In real flight, when they detect that a student pilot spends too much time looking inside the cockpit, instructors try to fix this incorrect gaze behavior with different methods. The less pervasive one is to orally notify the student, and the other one is to hide the information the student is focused on with an opaque paper. In this manner, the student understands that he or she has an incorrect behavior. However instructors do not have a tool to allow them to accurately analyze gaze behavior, so they cannot objectively detect deficient gaze behavior situations. Based on our observations and interviews, instructors use oral notifications as weaker warnings than visual notifications.

Furthermore, a major challenge is the growing use of Flight Training Devices (FTD) in pilot training in general and military aviation. FTD are largely used to train pilots at reduced costs [7]. There is also evidence that flight simulators are useful for ab-initio flight training [8][21] regarding instruments skills [7] even if the FTD is a low cost simulator (i.e. ordinary personal computer using commercial software $[9,10])$. However, the use of flight simulators has some drawbacks. One example shown by Johnson, Wiegmann and Wickens [11] is the different gaze behavior induced by the analog cockpit and the glass cockpit on a simulator. In this experimentation, pilots using an analog cockpit (control group) spent approximately $40 \%$ of their time looking out the window, instead of the $67 \%$ to $75 \%$ recommended allocation of attention to the outside world [12, 13]. Even more significantly pilots using a glass cockpit allocated only $10 \%$ of their visual attention to the outside world. One of the most effective teaching devices (simulators) may actually increase the incorrect "too much head-down time" behavior.

In this paper, the "head-down time" issue regarding the glass cockpit environment in a training context will be addressed. A commercial eye tracking system will be adapted to be used in a glass cockpit flight training device. An apparatus has been developed to allow real-time collection and analysis of gaze behaviors in order to efficiently teach French military trainees the correct patterns.

\section{Experiment}

The first goal of our experimentation is to reduce the head-down time to approach the recommended standard of $30 \%[12,13]$. More particularly the question here is to 
discover if real-time assistance based on notifications allow a reduction in head-down time. The other goal is to assess the effectiveness of the methodology currently used by the French Air Force in simulated flights. In this aim, we would like to validate our observations and assess if oral notifications are weaker warnings than visual ones.

In our experimentation, we will analyze gaze behavior in real-time, and send notifications in case of non-recommended gaze behaviors. Since the standard 30\% ratio of looking outside time is only applicable on the entire flight duration, we chose another criterion that allowed us to detect inappropriate gaze behavior in real-time. As instructors recommend not looking for more than 2 seconds at the inside of the cockpit we opted for this rule to trigger notifications. We call it the " 2 sec rule".

To conduct our experimentation, we designed an environment composed of a high fidelity, dynamic and interactive simulation [14] with a head mounted eye tracker. At this point, the real difficulty was to build a robust architecture to allow our eye tracker to interact in real-time with our simulation environment.

\subsection{Eye Tracker Constraints}

Recording, analyzing the location of the gaze and reacting to particular gaze behaviors in real-time, were the main challenges to address in this experiment. Moreover, the simulated environment setup brings too many constraints: five screens ( 3 for the outside world and 2 for the cockpit) and free head movements. This is why we opted for a head-mounted eye tracking solution. This eye tracker has two cameras: (1) one right eye focused camera responsible for the pupil position and size and (2) one for the recording of the environment (located between the eyes). Since this experimentation was not a study of usability or user experience, participant satisfaction was not tested. Our system does not have the vocation to be delivered to the French Air Force Academy or other training organizations. Participants in the experiment are subjects and under no circumstances final users.

To achieve our needs, the gaze location had to be known in real-time. We needed to find a robust and effective algorithm able to access and treat the adjusted gaze location thanks to head movements. The head movements could be detected thanks to a reference image which is captured at the beginning of the experimentation and tracked in real-time until the end of this experiment. Therefore a part of the solution was to use the OpenCV toolkit and the Surf algorithm [20] to track the location of the reference image in the picture provide by the environment camera.

However, the mounted eye tracking solution in our possession does not provide any suitable real-time gaze processing tools therefore we had to implement a specific module. The current gaze location is processed with a homographic computation between the gaze location in the reference image and the location of this reference image in the picture provide by the environment camera. This treatment takes time; nevertheless we achieved a suitable recording rate with 30 samples per second.

Furthermore, three static Areas of Interest (AOI) were defined (Fig 1): one for the outside world, and two for the cockpit, the PFD and MFD respectively. The outside world area contains the three screens showing the flight simulator view, while the two others show a cockpit simulator view. In our experimentation, the "2 sec rule" is only 
applicable to the time spent inside the PFD. In order to display visual notifications on the simulators screens (flight and cockpit), we developed another module with a windows overlay technique (shadow mask).

The first module which treats the gaze localization in real-time and analyzes behavior communicates with the other module responsible for showing visual notifications. We have made this possible thanks to the IVY data bus [15]. During the experimentation different data sources were collected and merged. The data is sent on this same logical bus IVY [15] and the data fusion is performed thanks to the time synchronization provided by a NTP server (Network Time protocol).

Our architecture is modular and handles the following constraints: temporal synchronization, modular communication, data logging and modular visual notifications.

\section{$2.2 \quad$ Participants}

Fifteen male students from the French Air Force (FAF) academy participated in the experiment. The students' total sailplane flight experience ranged from 5 to 100 hours (mean $=37 \mathrm{SD}=22,58$ ) and their ages ranged from 21 to 27 (mean $=22,4 \mathrm{SD}=1$, 99).

\subsection{Materials and Procedure}

The participant's task was to navigate from Ajaccio to Solenzara (Corsica, France) in a Cirrus Perspective flight simulator. The glass cockpit of the Cirrus Perspective is a Garmin 1000. The left screen (Primary Flight Display, PFD) presents the airplane attitude information (speed, altitude, heading... see figure 1). The right screen presents engine information (MFD, see Figure 1). No GPS navigation or any automation was allowed. Thus the student pilots had to fly with rudder and stick. The navigation duration was 31 minutes. Three horizontal screens showed the outside world.

Participants had to follow 31 altitude and heading instructions given orally while keeping constant speed (120kt). Altitude and heading instructions were given every minute. Each student was told of the security recommendation not to look at instrumentation (inside the cockpit) for more than 2 seconds. They were divided into three different condition groups (5 students per condition). There was (1) a control condition which did not trigger notification when the 2 seconds rule was violated (2) and two experimental groups which each received audio and visual notifications. To match with reality, the design of notifications was made from the observation we performed. Therefore one audio notification which announced in a synthetic voice the "look outside" advice (sound condition) while the other visual notification (visual condition) hid all information on the PFD. In the sound condition, the audio notification was played continuously until the participant's gaze was moved away from the PFD. In the visual condition, a black screen was displayed and masked entirely the PFD until the participant's gaze had left the PFD.

To run our experimentation, we used Xplane 9.0 as a flight simulation and we recorded simulated aircraft locations. The head mounted eye tracker was the Pertech 
solution with an accuracy of $0.3^{\circ}$ at $50 \mathrm{hz}$. We computed the head movement and the gaze correction with a third computer: Core i7 2.2gh, 8Go ram. We developed our software with visual Studio and C\#.

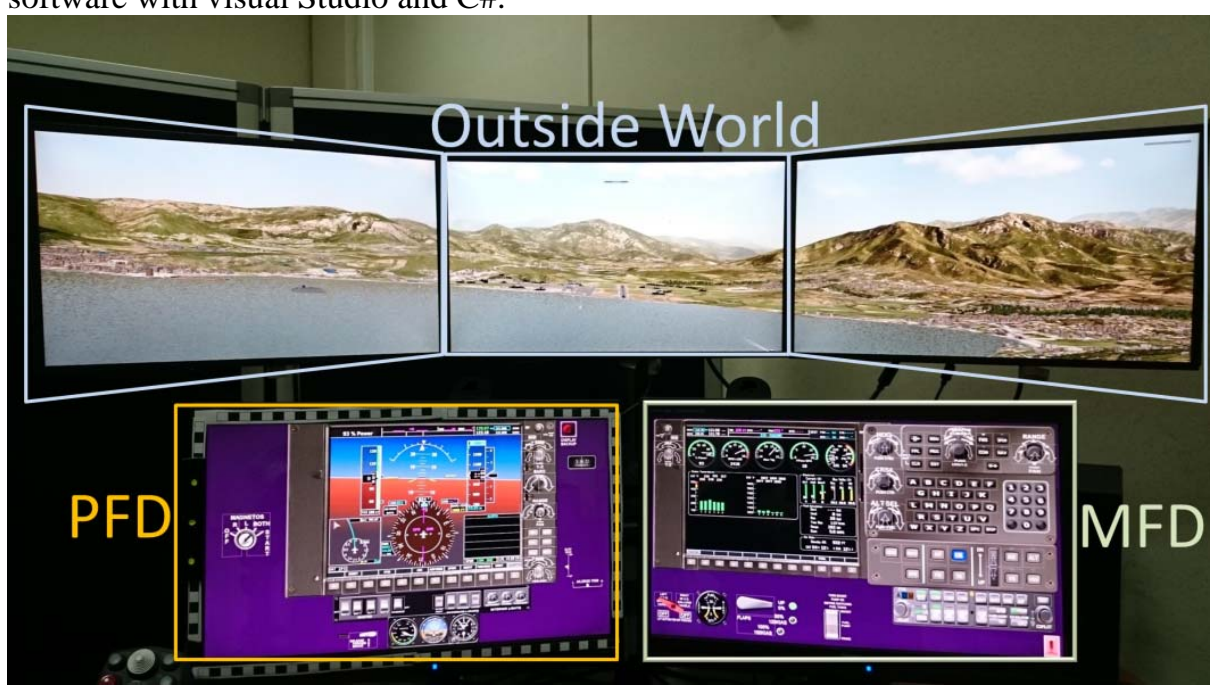

Fig. 1. Cirrus Perspective with Garmin 1000 simulator environment (CReA)

Two dependent variables were recorded. The first was the percentage of time spent looking at the PFD during the entire navigation. The expected effect of the notifications was to reduce the time spent looking inside at the PFD in the two experimental conditions compared to the control condition.

The second recorded dependent variable is the number of " 2 sec rule" violations. This number does not directly correspond to the number of notifications triggered because, in the control condition no notification was triggered. In order to allow a comparison, we analyzed in post-treatment the number of times they had exceeded the " 2 sec rule" for all participants. The expected effect was a lower number of " 2 sec rule" violations in the two experimental conditions compared to the control condition.

\section{$3 \quad$ Results}

\subsection{Percentage of Time Spent Inside PFD}

The figure 2 presents our results for the three groups of participants (control group, sound group, visual group) as a function the percentage of the time spent looking inside at the PFD during the entire navigation. 


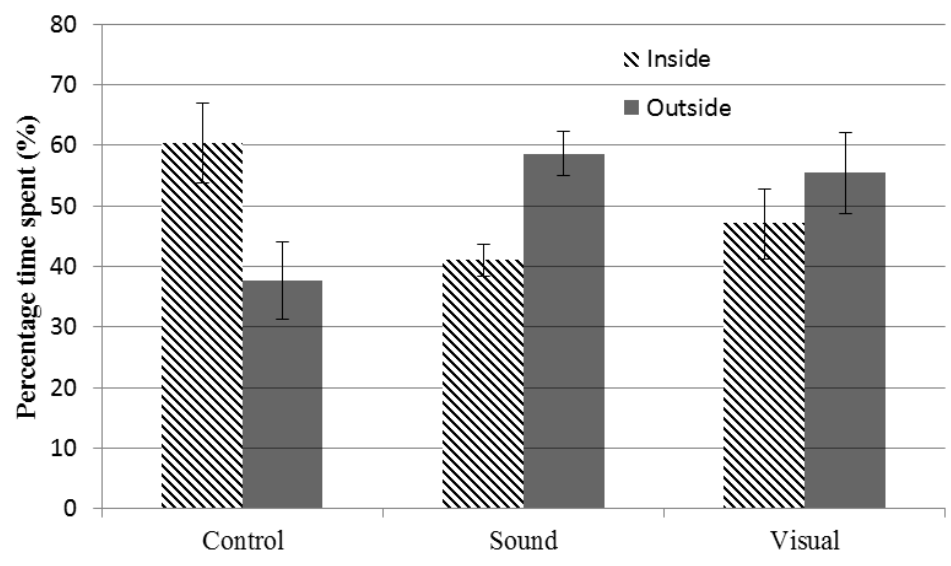

Fig. 2. Percentage of time spent inside and outside, averaged per condition. Error bars are standard errors.

An ANOVA was conducted for the average percentage of time spent looking inside (control group $=60.41 \%$, $\mathrm{SD}=14.8$; sound group $=41.00 \%$, $\mathrm{SD}=5.98$; visual group $=47.09 \%$, SD $=12.97)$. The results show a difference between the three conditions which is close to being significant $F(2,12)=3.49$; $\mathrm{MSE}=492.46 ; \mathrm{p}=0.063$. $\mathrm{T}$ tests were conducted between these three means and show that the control group (1) is higher than the sound group $t(4)=4.73 ; \mathrm{p}<.01$ and (2) tends to be higher than the visual group $t(4)=2.71 ; \mathrm{p}=.053$. However, the difference between sound group and visual group is not significant $t(4)=1.35 ; \mathrm{p}>.05$.

Another ANOVA was conducted for the time spent looking outside percentage (control group $=37.62 \%$, SD $=14.31$; sound group $=58.66 \%, \mathrm{SD}=8.04$; visual group $=55.45 \%, \mathrm{SD}=14.95)$. The results show a significant difference between the three conditions $F(2,12)=3.91$; MSE $=642.78$; $\mathrm{p}<.05$. T test was conducted between these three means and shows that the control group (1) is higher than the sound group $t(4)=7.33 ; \mathrm{p}<.01$ and (2) tends to be significantly higher than the visual group $t(4)=2.62 ; \mathrm{p}=.058$. However, the difference between the sound group and visual group is not significant $t(4)=0.51 ; \mathrm{p}>.05$.

\subsection{Number of " 2 sec rule" Violations.}

Although the time spent looking inside and outside was analyzed over the whole duration of the experiment, the decision was taken to analyze this second dependent variable every minute. For every altitude and heading instruction, participants repeated the same task. Consequently this way of analyzing the data was more relevant.

An ANOVA was conducted for the number of "2 sec rule" violations (control group $=5.29, \mathrm{SD}=0.83$; sound group $=2.82, \mathrm{SD}=0.9$; visual group $=2.49, \mathrm{SD}=$ 1.11; see Fig. 3). 


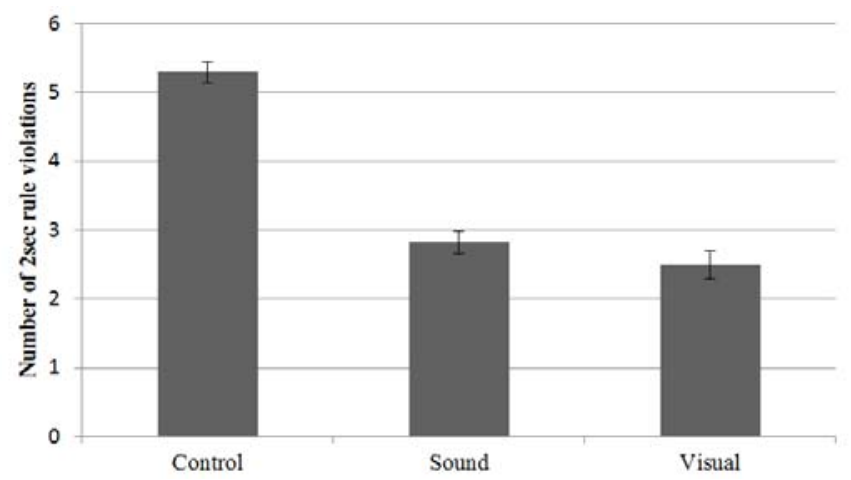

Fig. 3. Number of "2 sec rule" violations per minute, averaged per condition. Error bars are standard errors.

The results show a difference between the three conditions $F(2,90)=79.461 ;$ MSE $=$ 72.612; $\mathrm{p}<.001$. $\mathrm{T}$ test was conducted between these three means and show that the control group is higher than the sound and the visual group $t(30)=12.06 ; \mathrm{p}<.001$ and $t(30)=15.57 ; \mathrm{p}<.001$ respectively. However, the difference between the sound group and visual group is not significant $t(30)=1.58 ; \mathrm{p}>.05$.

\section{Discussion}

In this paper, we investigated trainee pilot gaze behaviors during simulated flights thanks to an eye tracker device. Participants (French Air Force student pilots) were notified by a verbal message or by a visual black screen on the PFD each time they spent more than 2 seconds looking at the PFD. Two dependent variables were assessed (1) the percentage of time spent looking at the PFD and (2) the number of notifications presented to participants. The objectives of this study are both to assess the effectiveness of real-time warning notification in a flight simulator environment and to evaluate the relative impact of the oral and visual notifications.

In our experimentation, we first tried to observe the standard $30 \%$ of flight time looking inside the cockpit $[12,13]$. In the control condition, in which no notification was displayed, the trainees recorded a figure of $60 \%$ of flight time looking at the PFD while in the sound and visual condition the figures were $41 \%$ and $47 \%$ respectively. The effects of our notifications are not enough to achieve the required standard. However this allows student pilots to produce behavior close to that of experienced pilots. Johnson, Wiegmann and Wickens [11] showed, with experienced pilots, the time spent looking inside the cockpit (analogical cockpit) is close to $40 \%$. The results also showed that the time spent looking elsewhere than at the PFD was transferred to the time spent looking outside. The control condition participants spent only $37 \%$ of their time looking outside, the sound and visual condition participants spent respectively $58 \%$ and $55 \%$. The obedience of the " 2 sec rule" was analyzed in order to check that student pilots do not spend too much time looking at the PFD between two periods 
looking at the outside world. The number of " 2 sec rule" violations is greatly reduced when notifications are triggered. While in control condition the number of violations is higher than 5 on average (5.29) per minute, with the sound and the visual condition, we found less than 3 on average (respectively 2.82 and 2.49). These results are congruent with the reduction of time spent looking at the PFD.

This study shows that the methodology used in the experiment has an effect on the student pilot gaze behavior. Time spent looking inside the cockpit is drastically reduced and approaches the standard figure. In the same way, notifications reduce the number of "2 sec rule" violations. The effect of this methodology could lead to improve flight safety.

Regarding the second objective, there is no significant difference between audio and visual notifications either in terms of time spent looking (1) inside and (2) outside, or of " 2 sec rule" violations. These results suggest, in a piloting assistance context ${ }^{1}$, that visual notifications bring no particular advantage compared to audio notifications (as expected from the military instructors' interviews) in a simulated flight environment.

However in a learning assistance context, rather than in the context detailed in this paper, differences between these two kinds of notifications could be found. As future work, one could evaluate the " 2 sec rule" internalization using a post test methodology without any notification. This is a relevant question since audio notifications only inform whereas visual notifications force to look elsewhere. As mentioned by some psychology studies [16, 17], the degree of internalization (memorizing) of a behavior is linked to the deliberate choice of a behavior. A free choice behavior has a larger probability to be acquired than a forced choice. In our experiment the sound condition can be compared to a "free choice" and the visual condition can be compared to a "forced choice". For example, the evaluation of the internalization of the " 2 sec rule" can be different, for these two conditions, in a post test (a few days after the experiment). This could be developed in another experimentation.

This study demonstrates a method of real-time warnings which allow an initial behavior to be changed to a targeted behavior. The methodology might help to create a more accurate scan pattern than the one used in this study (i.e., the ratio of time spent looking inside / outside the cockpit).

For instance, it may be useful to help novice pilots adopt practices similar to those of experienced pilots. In this aim it would be necessary to analyze more deeply the visual scan path of experienced pilots. We plan to analyze gaze data with interactive visualization tools [18] and processing algorithms [19]. Edge bundling algorithms have already proven to be an efficient tool to extract gaze patterns and thus will provide visual clues to assess the change of gaze behavior linked to the type of notification (audio or visual). As a future development, we also plan to use multiple eye tracker sources and to perform data fusion in order to improve gaze pattern detection. This gain of accuracy will require specific computation algorithms to perform the study in real-time and will be a technical challenge for future work.

\footnotetext{
${ }^{1}$ treating only of the punctual effect of notifications on gaze behavior during a simulated flight
} 


\section{Conclusion}

This study shows that novice pilots fail to avoid the "too much head-down time" glass cockpit pitfall. However, with a real-time warning notification, this pitfall can be drastically reduced. Ocular behavior comes close to that of the official standard with real time warnings, while with no assistance it is still very far from this standard. The effect of this notification may increase flight safety.

Two practical consequences can be derived from these results. Firstly, this technology can be a good way to improve simulated flight pedagogy and reduce some of the drawbacks of the glass cockpit. However this statement can only be correct from a learning perspective. This current study does not enable us to reach such a conclusion and this point deserves further investigation as previously. And from a more general standpoint, it may be very beneficial to consider these results in any circumstance where people have to monitor a complex system (aircraft, drone system, nuclear plant etc.). Eye tracking devices can be considered as monitoring tools, in addition to being efficient teaching instruments.

Acknowledgement This study is supported by the "Direction Générale de l'Armement” (DGA).

\section{$6 \quad$ References}

1. Dahlstrom, N., Dekker, S., \& Nahlinder, S. (2006). Introduction of technically advanced aircraft in ab-initio flight training. TECHNICAL REPORT, (2006-02).

2. Lindo, R. S., Deaton, J. E., Cain, J. H., \& Lang, C. (2012). Methods of instrument training and effects on pilots' performance with different types of flight instrument displays. Aviation Psychology and Applied Human Factors, 2(2), 62.

3. Federal Aviation Administration (1998b). Scanning for Other Aircraft. Aeronautical Information Manual, 8-1-6-c. Oklahoma City, OK: Author.

4. Colvin, K. W., Dodhia, R. M., Belcher, S. A., \& Dismukes, R. K. (2003). Scanning for visual traffic: An eye tracking study. In Proceedings of the 12th International Symposium on Aviation Psychology (pp. 255-260). Dayton, OH, USA: The Wright State University.

5. Rudisill, M. (1994). Flight crew experience with automation technologies on commercial transport flight decks. Human performance in automated systems: Current research and trends, 203-11.

6. Aircraft Owners \& Pilots Association. Air Safety Institute. (2012). The Accident Record for TAA. Frederick: AOPA Foundation. Institute, A. S. (n.d.). The Accident ecord of the Technically Advanced Aircraft. Aircraft Owners and Pilots Association.

7. Rantanen, E. M., \& Talleur, D. A. (2005, September). Incremental Transfer and Cost Effectiveness of Groundbased Flight Trainers in University Aviation Programs. In Proceedings of the Human Factors and Ergonomics Society Annual Meeting (Vol. 49, No. 7, pp. 764-768). SAGE Publications.

8. Macchiarella, N. D., Arban, P. K., \& Doherty, S. M. (2006). Transfer of training from flight training devices to flight for ab-initio pilots. International Journal of Applied Aviation Studies, 6(2), 299-314. 
9. Taylor, Henry L., et al. (2002). Incremental training effectiveness of personal computer aviation training devices (PCATD) used for instrument training. University of Illinois at Urbana-Champaign, Aviation Research Lab, 2002.

10. Taylor, H. L., Talleur, D. A., Emanuel Jr, T. W., \& Rantanen, E. M. (2005). Transfer of training effectiveness of a flight training device (FTD). In Proceedings of the 13th International Symposium on Aviation Psychology (pp. 1-4).

11. Johnson, N., Wiegmann, D., \& Wickens, C. (2006, October). Effects of advanced cockpit displays on general aviation pilots' decisions to continue visual flight rules flight into instrument meteorological conditions. In Proceedings of the Human Factors and Ergonomics Society Annual Meeting (Vol. 50, No. 1, pp. 30-34). Sage Publications.

12. AOPA Air Safety Foundation (1993). How to avoid a midair collision. January 16.

13. FAR/AIM (2003). Aeronautical Information Manual/ Federal Aviation Regulations. McGraw-Hill.

14. Eyrolle, H., Mariné, C., \& Mailles, S. (1996). La simulation des environnements dynamiques: intérêts et limites. Cellier, JM, De Keyser, V., Valot, C., La gestion du temps dans les environnements dynamiques. PUF, Paris, 103-121.

15. Buisson, M., Bustico, A., Chatty, S., Colin, F. R., Jestin, Y., Maury, S., ... \& Truillet, P. (2002, November). Ivy: un bus logiciel au service du développement de prototypes de systèmes interactifs. In Proceedings of the 14th French-speaking conference on Humancomputer interaction (Conférence Francophone sur l'Interaction Homme-Machine) (pp. 223-226). ACM.

16. Kiesler, C. A. (1971). The psychology of commitment: Experiments linking behavior to belief. New York: Academic Press.

17. Joule, R. V., \& Beauvois, J. L. (1998). La soumission librement consentie: comment amener les gens à faire librement ce qu'ils doivent faire?. Presses universitaires de France.

18. Hurter, C., Tissoires, B., \& Conversy, S. (2009). FromDaDy: Spreading data across views to support iterative exploration of aircraft trajectories. IEEE TVCG, 15(6), 1017-1024.

19. Hurter, C.; Ersoy, O.; Fabrikant, S.; Klein, T.; Telea, A. (2013). Bundled Visualization of Dynamic Graph and Trail Data. (TVCG) Visualization and Computer Graphics

20. Herbert Bay, Andreas Ess, Tinne Tuytelaars, Luc Van Gool. SURF: Speeded Up Robust Features, Computer Vision and Image Understanding (CVIU), Vol. 110, No. 3, pp. 346359, 2008.

21. Stewart, J. E., Dohme, J. A., \& Nullmeyer, R. T. (2002). US Army initial entry rotarywing transfer of training research. The International Journal of Aviation Psychology, 12(4), 359-375.

22. Wright, S., \& O'Hare, D. (2015). Can a glass cockpit display help (or hinder) performance of novices in simulated flight training?. Applied ergonomics, 47, 292-299. 